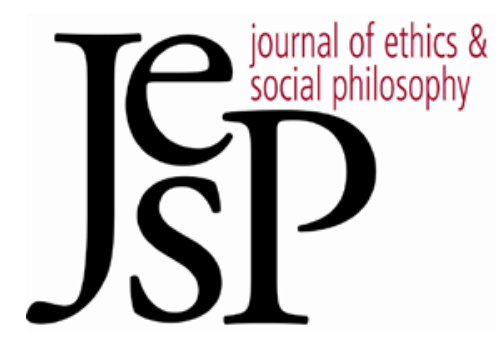

\title{
Liberalism or Immigration Restrictions, But Not Both
}

By Christopher Freiman And Javier Hidalgo

JOURNAL OF ETHICS \&SOCIAL PHILOSOPHY

VoL. 10, NO. 2 | MAY 2016 URL: WWW.JESP.ORG COPYRIGHT @ C CHRISTOPHER FREIMAN AND JAVIER HIDALGO 2016 


\section{Liberalism or Immigration Restrictions, But Not Both}

Christopher Freiman and Javier Hidalgo ${ }^{1}$

I MAGINE A STATE, CALL IT RESTRICTIVELAND, that lets you worship in a Mormon church - just not after 6 p.m. Publishers can print the Communist Manifesto - just not more than 5,000 copies per year. And you are free to major in folklore and mythology - just as long as the country's total majors have not exceeded 300 .

No doubt RestrictiveLand's policies are strange. But it has its reasons. At the margins, these restrictions will tilt the country's culture, politics and economy in a way that most of its citizens prefer. What is more, the restrictions were arrived at democratically. After all, RestrictiveLanders claim, citizens have a collective right of self-determination over their country. And in any case, it is not as though these restrictions obliterate freedom of religion, speech or educational choice; they just trim them down.

Whatever you think about the desirability or justness of RestrictiveLand, one thing is for sure: it is not liberal. And most would not accept RestrictiveLand's reasons for restricting people's liberty to speak or worship. But note: its reasons are precisely the same as those that many philosophers give for restricting people's liberty to immigrate.

This paper argues for a dilemma: you can accept liberalism or substantive immigration restrictions, but not both. More specifically, the standard arguments for restricting freedom of movement apply equally to textbook liberal freedoms such as speech, religion, reproduction, occupational choice and bodily choice.

We begin with a sketch of liberalism's core principles and an argument for why freedom of movement is plausibly on a par with other liberal freedoms (Section 1). Next we argue that, if a state's right to self-determination grounds a prima facie right to restrict immigration, then it also grounds a prima facie right to restrict liberal freedoms such as speech, religion, sexual choice and more (Section 2). We then suggest that the social costs associated with freedom of immigration are also costs associated with occupational choice, speech and reproduction. So a state's interest in reducing these costs gives it prima facie justification to restrict not only immigration but also other core liberal freedoms (Section 3).

Of course, even if the standard arguments for a prima facie right to restrict immigration also support a prima facie right to restrict liberal freedoms generally, there might be differences that render immigration restrictions but not restrictions on speech, religion, etc. - justified all things considered. We consider arguments along these lines and provide replies (Section 4). In closing, we suggest that the theoretical price of supporting immigration re-

1 The authors wish to note that the order of authorship was determined alphabetically and that the authors' contributions to the article were equal. 
strictions - viz., compromising a commitment to liberal principles - is too steep to pay (Section 5).

\section{Liberalism and Freedom of Movement}

Although we lack the space to provide anything approaching a comprehensive account of liberalism, we will sketch a brief outline in this section. Then we will make a prima facie case for the claim that the liberty to immigrate deserves a place among the basic liberties prioritized by liberals. We defend this claim against objections in Section 4.

To begin, let us spotlight three claims endorsed by most liberal views. First, whatever their theoretical differences, all liberals agree on at least a core list of policy proposals. To even qualify as a liberal, you must endorse the importance of protecting so-called "basic" liberties such as freedom of speech, freedom of the press, freedom of religion, freedom of association, occupational freedom, freedom of bodily choice, reproductive freedom and so on.

Beyond these specific policies, liberals generally agree about how the justification of policy is structured. The initial burden of justification resides with those who would restrict liberty rather than those who would exercise it. Gerald Gaus sees this presumption of liberty stretching back to Locke, who says that in the state of nature people are in "a State of perfect Freedom to order their actions ... as they see fit ... without asking leave, or depending upon the Will of any other Man."2 Gaus himself says the claim that "all interferences with action stand in need of justification" is the fundamental liberal principle. ${ }^{3}$

The list goes on. John Stuart Mill says that "the burden of proof is supposed to be with those who are against liberty; who contend for any restriction or prohibition ... The a priori assumption is in favor of freedom." 4 Joel Feinberg writes, "Most writers on our subject have endorsed a kind of 'presumption in favor of liberty.' ... Liberty should be the norm; coercion always needs some special justification." 5 According to Feinberg, this presumption shifts "the burden of argument to the shoulders of the advocate of coercion who must, in particular instances, show that the standing case for liberty can be overridden by even weightier reasons on the other side of the scales." Stanley Benn says, "The burden of justification falls on the interferer, not on the person interfered with." Writing specifically of the Rawlsian

\footnotetext{
2 Locke (1960: 287).

3 Gaus (2005: 272).

${ }^{4}$ Mill (1963: 262).

${ }^{5}$ Feinberg (1987: 9).

${ }^{6}$ Ibid.

7 Benn (1988: 87).
} 
take on liberalism, Samuel Scheffler remarks, "Coercion always requires justification, and this requirement is particularly urgent with respect to the coercive political power of the state ... [G]iven the status of individuals as free and equal, the establishment of coercive institutions poses a special justificatory problem."”

To be clear: although the previous paragraph emphasizes so-called "negative liberty" or rights of non-interference, liberals also prioritize so-called "positive liberty" or the substantive freedom to form and effectively pursue your own conception of the good. We focus on non-interference simply because we will argue that immigration restrictions violate negative liberty that is, they involve coercive interference. According to defenders of the presumption against coercive interference, one important reason why coercion is a prima facie wrong that stands in need of justification is that it forcibly subordinates the coerced party's judgment to another's. This kind of subordination is at odds with the liberal picture of people as free and equal moral agents. Michael Huemer writes: "coercion requires a justification. This may be because of the way in which coercion disrespects persons, seeking to bypass their reason and manipulate them through fear, or the way in which it seems to deny the autonomy and equality of other persons." 9

So liberals think that the burden of justification rests with restrictors of liberty. Of course, that burden can be met. But how? This question brings us to the third relevant liberal principle: generally speaking, the kinds of reasons that can defeat the presumption of liberty are themselves liberty-based reasons. Rawls, for instance, says that each person is entitled, as a matter of right, to "the most extensive total system of equal basic liberties compatible with a similar system of liberty for all" and, crucially, that "a basic liberty ... can be limited only for the sake of liberty itself." 10 For instance, the liberty of the press to run political advocacy pieces can be restricted for the sake of citizens' equal liberty to influence the political process. But liberty has priority over competing values such as economic growth, moral virtue or cultural development. Even if we would produce a morally better populace by banning college freshmen from reading Nietzsche, a liberal state would not do it. You might follow Rawls in assigning liberty lexical priority over other values, meaning that reasons of liberty unconditionally defeat reasons of any other sort. But it is also reasonable to assign liberty top political priority while acknowledging that sufficiently weighty reasons of another sort might be enough to defeat it. (This distinction will not matter for our purposes.)

Now we can put some more meat on the bones of our argument. We will start by arguing that freedom of movement is a basic liberty alongside

${ }^{8}$ Scheffler (2010: 154).

${ }^{9}$ Huemer (2013: 10).

${ }^{10}$ Rawls (1999: 220, 179). 
uncontroversial basic liberties such as freedom of association and occupation. If so, then there is a presumption against restricting freedom of movement just as there is a presumption against restricting these other liberties. Subsequent sections examine some popular reasons given in support of restricting immigrants' freedom of movement. We argue that, on any kind of liberal view, these reasons are not sufficient to overcome the presumption of liberty and thus justify restricting a basic liberty. They appeal to economic or cultural considerations, considerations that are always or at least typically outweighed by considerations of liberty. Lastly we consider whether a state might have weaker reasons not to restrict foreigners' freedom of movement than not to restrict citizens' freedom of association, occupational choice and so on.

The rest of the section makes the prima facie case for the claim that freedom of movement is a basic liberty. In the interest of space, we will not take a stand on why basic liberties are valuable. There are surely many reasons why: they protect personal autonomy, allow us to pursue the projects that we value, protect basic human interests, create social and political conditions that enable the development of, in Rawls' terms, our two moral powers, keep our options open in case we change our minds about what we value and so on. We think that freedom of movement can be defended as a basic liberty on all of these grounds but we lack the space to do so here. So we will take what we think is the most straightforward route to showing that freedom of movement is a basic liberty - namely, by showing that it is a constituent part of other liberties that all liberals think are basic. That is, freedom of movement has value in virtue of the fact that it is a component of basic liberties. We will focus on the relationship between freedom of movement and rights to occupational freedom and freedom of association, although freedom of movement may be a component of other valuable liberties as well.

According to a standard liberal view, it is presumptively unjust for states to restrict people's freedom to pursue different occupational options and associate with other people as they see fit. Liberals would say that it is wrong for the state to forbid one from switching jobs, pursuing a new career, renting an apartment with one's friends, joining the local church, and other exercises of freedom of occupation and association. Of course, the presumption against state interference can be overridden. For instance, the state can interfere with your project of becoming a hit man. But liberals think that states need strong reasons for interfering with freedom of association and occupational choice.

Freedom of occupation and association require freedom of movement. Suppose that the government prohibits you from, say, traveling to your place of employment or your local church. You have a right against government interference with your freedom of occupation and association and, to respect this right, government agents must refrain from interfering with your free- 
dom of movement. Furthermore, restrictions on freedom of movement also constrain other people's freedom of association. In the above example, restrictions on your freedom of movement interfere with your employer and congregation's freedom to associate with you on voluntary terms. Consider another example. Imagine that you live in Newark, New Jersey, and you find a job in Los Angeles, California, where many of your friends and family also happen to live. State employees would abridge your freedom of occupational choice and association, and the freedom of the people in Los Angeles who want to associate with you, if they coercively stopped you from moving to Los Angeles.

As these examples illustrate, freedom of movement is a constitutive component of other basic liberties. Your freedom to move to Los Angeles just is an extension of your freedom of occupational choice and association. ${ }^{11}$ Thus, if the state significantly restricts your freedom of movement, it also usually restricts your freedom of occupational choice and association, as well as the freedom of people who wish to associate with you. ${ }^{12}$ Liberalism says that states have strong moral reasons to refrain from restricting occupational choice and freedom of association. So states have strong moral reasons to avoid restricting freedom of movement as well. This explains why domestic freedom of movement is widely regarded as a basic human right. Even philosophers who reject the view that people have rights to immigrate to other states acknowledge that people have human rights to freedom of movement within the borders of their states. ${ }^{13}$

Now, let us consider a new example. Imagine again that you live in Newark, but suppose that, instead of Los Angeles, you find a job in Vancouver, Canada, where your friends and family also happen to live. If it was wrong for government agents to restrict your freedom of occupation and

11 For a similar analysis of the value of free movement, see Carens (2013: 236-54); Oberman 2016. See also Kukathas (2005: 210).

12 It is important to make two distinctions here. First, not every restriction on freedom of movement is an infringement on occupational choice or association. Suppose that you want to build a spaceship and fly to Jupiter, but the government forbids you from doing this. This is a restriction on freedom of movement, but it does not seem to be a restriction on freedom of association or occupational choice. One difference between this case and the NewarkLos Angeles one is that there is no one on Jupiter to hire you or associate with you (although the freedom to fly to Jupiter may be valuable for other reasons). In contrast, when the government coercively prevents you from moving to a place where people could potentially hire or associate with you, then this is an infringement on your freedoms of association and occupational choice. Second, not every restriction on freedom of movement is impermissible. It is permissible for the government to forbid me from entering a military base, for example. But this fails to imply that freedom of movement is not an important liberty. States can also restrict other basic liberties in certain circumstances. To illustrate, most people think that states can permissibly restrict freedom of speech or occupational choice if there is a sufficiently compelling reason to do so.

${ }^{13}$ For example, see Blake 2003. 
choice by restricting your movement between Newark and Los Angeles, it is hard to see why it would be permissible for state employees to restrict your freedom to move to Vancouver. We can extend this argument to immigration restrictions in general. Immigration restrictions coercively infringe on the freedoms of foreigners and the freedoms of citizens who want to associate with these foreigners. Maybe there is some relevant difference between domestic and international freedom of movement on closer inspection, and we will consider some possible differences in the following sections. But this example suggests that, if occupational freedom and freedom of association require freedom of movement, then these freedoms require freedom of international movement as well.

With this analysis of the value of free movement on the table, it is easy to see why restrictions on immigration stand in tension with liberalism. Restrictions on freedom of movement interfere with freedom of occupational choice and association. So immigration restrictions conflict with core liberal freedoms. If liberalism requires the protection of freedom of occupational choice and association, then liberalism and immigration restrictions are prima facie incompatible. In the next two sections, we will generalize this result to other liberal freedoms. More precisely, we will argue that if prominent arguments of immigration restrictions succeed, then these same arguments can also justify restricting important liberal freedoms, such as freedom of speech, reproductive freedom and other liberties.

\section{Collective Self-Determination}

Some philosophers argue that states have rights to collective selfdetermination and that these rights justify immigration restrictions. According to this argument, states (or people organized in states) have rights to shape their future character and control their collective destiny. If states have rights to shape their collective destiny or control their character, then perhaps states also have rights to restrict immigration. Let us call this general argument for immigration restrictions the self-determination argument. Different authors develop the self-determination argument in different ways. Some political theorists argue that nations have rights to control their cultural character or preserve their national cultures. ${ }^{14}$ Other authors, such as Christopher Wellman, contend that states have rights to freedom of association. On this view, states are analogous to clubs and other voluntary associations in that they have rights to refuse to associate with nonmembers and these rights permit states to exclude foreigners. ${ }^{15}$ Some political theorists understand selfdetermination in terms of ownership. They think that citizens collectively

14 Walzer 1983; Miller 2005.

15 Cole and Wellman 2011. 
own their territory or political institutions and these ownership rights justify denying foreigners access to their collective property. ${ }^{16}$

Rights to self-determination are supposed to justify immigration restrictions in virtue of the fact that states have rights to control their future direction and character. In defending the right to exclude, Margaret Moore writes: "People have an interest in ensuring that, both individually and collectively, they have control over their lives, over the place that they live, and over the collective character of their community." ${ }_{17}$ David Miller defends immigration restrictions by arguing that "the public culture of their country is something that people have an interest in controlling: they want to be able to shape the way that their nation develops, including the values that are contained in the public culture."18 In a recent paper, Miller also says that a democratic state has "the right to determine its own future membership" and that states have interests in being able to control the number of people in their jurisdiction. ${ }^{19}$ Wellman argues that citizens have entitlements to exclude foreigners in part because "a country's immigration policy determines who has the opportunity to join the current citizens in shaping the country's future" and "this policy will matter enormously to any citizen who cares what course her political community will take." 20

Immigration can alter the character and composition of a community. For one thing, immigration increases a state's population density and, if immigrants gain political rights, they will exercise influence over a country's policies. Immigrants may also be culturally distinct from the native population and, consequently, immigration can cause cultural change. If citizens have entitlements to control the collective character or future shape of their political community, then it would seem to follow that states have rights to restrict immigration. Moreover, these rights would outweigh foreigners' interests in immigrating and citizens' interests in associating with foreigners. As we pointed out in Section 1, immigration restrictions restrict foreigners' occupational freedom and their freedom to associate with the citizens of other states. So, if rights to collective self-determination can justify immigration restrictions, then it must be the case that these rights justify restrictions on the freedoms of citizens and foreigners. Otherwise, the self-determination argument would be a nonstarter. That is, if rights to collective selfdetermination were unable to justify restrictions on the freedom of foreigners and citizens, then it would be false that rights to self-determination could explain why immigration restrictions are permissible.

To illustrate, consider the following case:

16 Pevnick 2014.

17 Moore (2015: 195).

${ }_{18}$ Miller (2005: 200).

19 Miller (2016: 29).

${ }^{20}$ Cole and Wellman (2011: 40). 
Immigration. Countries $\mathrm{X}$ and $\mathrm{Y}$ are adjacent to one another. Many of the citizens of $\mathrm{Y}$ want to immigrate to $\mathrm{X}$. But, if the citizens of $\mathrm{Y}$ immigrate to $\mathrm{X}$, they will change the character of X's culture and the composition of its membership.

Let us stipulate that $\mathrm{X}$ and $\mathrm{Y}$ are both legitimate states that adequately protect the human rights of their populations. Nonetheless, many of the citizens of $\mathrm{Y}$ want to immigrate to $\mathrm{X}$ because, say, they would like to find employment in $\mathrm{X}$, some of them have friends and family in $\mathrm{X}$ and they want to live near them, some of the members of $Y$ prefer the culture of $X$ and so on. Assume also that some of the citizens of $\mathrm{X}$ would like to associate with the citizens of $\mathrm{Y}$ as well by hiring them, living with them or near them and so on. If the self-determination argument is sound, then $\mathrm{X}$ has a right to restrict the citizens of Y's freedom to immigrate to $\mathrm{X}$ and the freedom of $\mathrm{X}$ 's citizens to associate with the residents of $\mathrm{Y}$. Why does $\mathrm{X}$ have this right? Immigration to $\mathrm{X}$ would change its character and demographics. If the citizens of $\mathrm{X}$ have a right to control these aspects of their community, then the citizens of $\mathrm{X}$ have a right to control immigration, despite the fact that restricting immigration constrains the freedom of people in both $\mathrm{X}$ and $\mathrm{Y}$.

But notice that the exercise of standard liberal freedoms can change the character of a community, too. Liberties such as freedom of speech, conscience and reproductive freedom can alter the composition of a community's membership and character. To motivate his argument for the right to exclude, Wellman draws analogies between states and private associations, such as clubs, private universities, businesses and marriages. ${ }^{21}$ Wellman contends that, just as these private associations can permissibly refrain from admitting new members, states have rights to refrain from admitting foreigners as well.

Notice, though, that rights to freedom of association are usually thought to justify more than the right to exclude nonmembers. Take Wellman's observation that private universities have rights to freedom of association. ${ }^{22}$ Private universities may, for example, set restrictions on students' freedom to distribute political pamphlets or hold protests in ways liberals would find intolerable if undertaken by the state.

Contrast Immigration with the following two other cases:

Speech. Some of the citizens of $\mathrm{X}$ adopt new norms, values and practices. Most of the citizens of $\mathrm{X}$ are Christians, but an increasing number of citizens convert to Buddhism. Most of the citizens of X only speak English, but a growing number of citizens decide to exclusively speak Spanish. Most of the citizens of X are political conservatives, but more and more citizens are starting to adopt liberal values and

${ }^{21}$ Ibid.: 35, 42, 66.

22 Ibid.: 42. 
vote for liberal candidates. These cultural and political changes occur because some citizens persuade other citizens to adopt new values and practices.

Reproduction. Some of the citizens of $\mathrm{X}$ have more children than the average. These citizens have cultural norms and political values that are different from most other citizens and the members of this group successfully pass these values down to their children. Because the reproductive rate of this group is higher than the average, their reproductive practices gradually alter the culture and demographics of X.

In Speech and Reproduction, the exercise of freedom of speech and reproductive freedom changes the composition of a state's membership, its culture and its character. Furthermore, let us stipulate that immigration to $\mathrm{X}$, the exercise of free speech and differential rates of reproduction would bring about similar changes to X's culture and character. That is, although the origin of these changes is different, immigration, speech and reproduction result in similar cultural and political changes in $\mathrm{X}$ across all three cases.

In Speech and Reproduction, do the citizens of $\mathrm{X}$ have rights to restrict freedom of speech or reproductive freedom in order to prevent these changes? Imagine that in each case the government of $\mathrm{X}$ could implement laws that effectively stop these cultural or demographic changes by restricting freedom of speech or reproductive freedom. In Speech, the government might censor countercultural speech, penalize people for speaking Spanish or try to discourage people from converting to Buddhism in order to prevent cultural and political change. Perhaps the government restricts Buddhists' freedom to associate and congregate with one another. In Reproduction, the government could prohibit citizens from having more than a certain number of children and, let us assume, this would slow population growth. If the citizens of $\mathrm{X}$ have rights to control the future shape and direction of their community, then it is hard to see why it would be permissible to restrict the freedom to immigrate but impermissible to restrict freedom of speech and reproductive liberty. The same considerations that justify the right to exclude immigrants from $\mathrm{Y}$ in Immigration - the entitlement to control a society's character and future direction - also seem to justify X's right to restrict freedom of speech and reproductive freedom at first glance.

A defender of the self-determination argument might respond by arguing that legitimate states only have rights to control cultural and demographic changes that are externally generated. Miller argues along these lines:

$[\Pi \mathrm{t}$ is often said, correctly, that societal cultures are always in flux, and that preventing immigration in order to "freeze" a culture at a particular moment of time is therefore absurd. But from the point of view of the people whose culture it is, it makes a difference whether the sources of change are internal or external. Sometimes, of course, people may welcome the introduction of new elements of culture from the outside, but this is different from having changes forced upon you by external factors that you cannot control. ... [C]itizens may still have an interest in re- 
sisting externally generated cultural change, and retaining control over immigration is one of the levers that allows them to do this. ${ }^{23}$

Miller's remarks suggest that we can draw a distinction between Immigration on the one hand and Reproduction and Speech on the other by pointing to the origin of the relevant changes. In Immigration, the origin of these changes is foreign. In Reproduction and Speech, the source of cultural and political change is domestic.

But this response is problematic. To see why, note that we can alter the examples to make the source of the relevant changes foreign. Suppose that the citizens of the adjacent country $\mathrm{Y}$ have published books that advocate in favor of converting to Buddhism.24 If the citizens of $\mathrm{X}$ read these books, some of them will be persuaded and decide to convert to Buddhism. If states have rights to restrict freedom in order to prevent externally generated changes, then it appears that the government of $\mathrm{X}$ has the right to restrict liberty in order to stop this change. For instance, the government of $\mathrm{X}$ might ban the importation of foreign books to prevent the spread of Buddhism or forbid citizens from selling or buying these books. So, even if states only have rights to restrict liberty in order to resist externally generated change, this still entails restrictions on liberal freedoms.

Maybe the important distinction is not about the pedigree of cultural changes. Perhaps the relevant distinction is instead between voluntary and involuntary change. Miller suggests this point when he writes: "people may welcome the introduction of new elements of culture from the outside, but this is different from having changes forced upon you by external factors that you cannot control." The point here seems to be that, if immigration causes a society's culture to change, then this change is forced on citizens and these citizens might have a legitimate interest in resisting this forcing. Yet liberals would deny that people have the right to restrict freedom in order to prevent involuntary cultural changes. Suppose that a group of religious conservatives lives in a culture that is rapidly becoming secular and liberal. These conservatives are unable to control or prevent this cultural change. Thus, this change is "forced" on religious conservatives. Nonetheless, it seems false that these conservatives have rights to restrict freedom of speech and other liberties in order to prevent this cultural change. Similarly, it is unclear why citizens would have rights to restrict the freedom to immigrate in order to stop cultural changes that are generated by immigration, even if many citizens dislike these changes.

Another response to our argument in this section is that liberal freedoms, such as free speech and reproductive freedom, are particularly weighty

${ }^{23}$ Miller (2016: 28).

${ }^{24}$ For a similar argument, see Sparrow (forthcoming). 
liberties, while the freedom to immigrate protects less important interests. Thus, while rights to self-determination can override the freedom to immigrate, these rights are unable to outweigh basic liberal freedoms. We will discuss this objection in greater detail in Section 4. But, as a first pass, this response fails to rebut our argument. Even if it is true that freedom of speech and reproductive freedom protect more important interests than the freedom to immigrate in general, it is false that freedom of speech and reproductive freedom always protect more important interests.

To illustrate, let us return to the case of Immigration. The members of $\mathrm{Y}$ may in general have stronger interests in exercising free speech and controlling their reproductive freedom than they do in immigrating to other states. But it is possible that the members of $\mathrm{Y}$ have stronger interests in immigrating than they do in exercising free speech or reproductive freedom at the margin. For example, the citizens of $\mathrm{Y}$ may have only weak interests in having more than five children or reading and publishing books that endorse Satanism, while many of them may have weighty interests in immigrating to X. If their interests in immigrating to $\mathrm{X}$ are weightier than their interests in exercising other liberal freedoms at the margin and rights to self-determination can justify restricting the freedom to immigrate to $\mathrm{X}$, then rights to selfdetermination should also justify restricting their liberal freedoms. So, although it is plausible that standard liberal freedoms do protect more important interests than the freedom to immigrate on average, it seems unlikely that this is true along every possible margin.

To sum things up, if states have rights to restrict immigration in virtue of the fact that they have rights to self-determination, then it appears that states can permissibly restrict basic liberal freedoms, such as freedom of speech, reproductive freedom and other important freedoms. Thus, one prominent argument for immigration restrictions - the self-determination argument - entails the rejection of liberalism. We will now show that other arguments for immigration restrictions have similar implications.

\section{Cost Arguments}

Some object to relaxing immigration restrictions on the grounds that doing so will carry significant social costs. This section addresses these sorts of "cost arguments" for restriction. We will grant, for argument's sake, that imposing coercive restrictions on immigrants' freedom of movement would spare us the costs in question. The trouble is, many other freedoms carry the same costs as freedom of immigration. But liberals are not willing to coercively restrict these freedoms to spare us the relevant social costs. And the reason is one we mentioned earlier - liberals prioritize liberty over competing values such as economic gains or the preservation of certain cultural norms as a matter of principle. Our aim in this section is to show that cost argu- 
ments for immigration restriction overgeneralize - they speak in favor of not only coercive restrictions on liberty of movement but also coercive restrictions on other liberties that no liberal would support.

So the section's basic thesis is this: standard reasons for restricting immigration liberty are also reasons for restricting other liberties. As noted, there might be countervailing reasons that defeat the case for restriction that apply to these other liberties but not to immigration. For instance, maybe the freedom to immigrate is not as important or basic as these other freedoms. Or perhaps states have stronger obligations not to coercively restrict the liberties of their own citizens. We will take up these objections in the next section.

\section{a. Overconsumption of government services}

A common argument for immigration restriction alleges that open borders would increase citizens' net tax burden because immigrants will tend to consume more in government services than they contribute in taxes.25 Suppose, for argument's sake, the relevant empirical claims are correct. Still, there are plenty of liberties whose exercise increases citizens' net tax burden. If a (sufficient) reduction in the general tax burden is a reason to coercively restrict freedom of movement, it is a reason to coercively restrict occupational choice, reproductive choice, rights of bodily control and so on.

For starters, consider unemployment benefits. The more citizens on unemployment, the higher the general tax burden. The state could spare its citizens these added costs by imposing restrictions on occupational and educational choice. Take the case of getting a $\mathrm{PhD}$ in philosophy from a state university. This choice can increase the general tax burden in (at least) three ways. First, your years of study are financed (partly) by public funds. Second, an increasing number of students are turning to government assistance such as food stamps to support themselves during graduate school. And third, suppose that dedicating yourself to completing a philosophy $\mathrm{PhD}$ places you at risk of long-term unemployment (it requires a leap of imagination, we know) and thus raises your probability of needing unemployment benefits. Or let us make it simpler: you quit your job because you hate your boss's shirts. As a result, you find yourself on unemployment. If sparing citizens an increased tax burden is a prima facie justification for restricting freedom of movement, it also seems to supply a prima facie justification for restricting occupational choice.

Along similar lines, consider the freedom to dispose of one's personal property. You are within your rights to chop down your house, burn your remaining possessions in a bonfire and give away your land to the next-door

25 See, e.g., Woodward 1992; Heath 1997; Isbister 2000. 
neighbor (maybe you have read some Thoreau and gone overboard). But now you will need public assistance to get adequate housing, food and health care. So it looks as though there is reason for the state to coercively restrict your ability to chop down your house. Liberals also think that people possess strong rights of bodily control that entitle them to have unprotected sex, climb Mount Everest and eat a dozen sleeves of Oreos in one sitting. But here again, all of these activities come with significant health risks and thus the potential for increasing public health care costs. Indeed, exercising your reproductive freedom by, say, having a fourth child, increases the general tax burden. After all, this child is likely to attend public schools, use the emergency room and so on.

\section{b. Wage effects}

Another objection is that immigrants will increase the supply of low-skilled labor and thus decrease wages in certain sectors of the domestic economy. Indeed, this result would harm those citizens who are already likely to be worse off.

It is worth noting that recent studies suggest that increased immigration causes a modest long-term increase in the real wages of the average domestic worker. ${ }^{26}$ But there is also evidence that immigration causes a roughly 5 percent drop in the wages of those lower-skilled, native-born workers who directly compete with immigrant workers. ${ }^{27}$

Of course, immigration is far from alone in having this adverse effect on the wages of low-skilled, native-born workers. A clear example is outsourcing labor to foreign countries. ${ }^{28}$ Indeed, outsourcing puts native-born workers in direct competition with foreign labor in much the same way that immigration does. A firm's ability to hire workers in a foreign country for comparatively low wages exerts downward pressure on the wages of domestic workers just as a firm's ability to hire immigrants within a country for comparatively low wages exerts downward pressure on the wages of domestic workers.

Or consider technological innovation and automation. Baxter is a $\$ 25,000$ industrial robot that loads and sorts boxes. The possibility of placing Baxter on an assembly line will make it hard for production workers to demand higher wages. Over time, as the technology becomes cheaper, the wages of these workers will decrease as well. The same goes for automated ordering kiosks that take the place of cashiers.

26 See, e.g., Peri and Sparber 2009; Ottavino and Peri 2012; Peri 2012; Dustmann, Frattini and Preston 2013.

27 National Research Council (1997: 7); Ottaviano and Peri (2012: 191).

${ }^{28}$ For a similar point, see Kukathas (2005: 213). 
Occupational freedom more generally can have the same effect. Suppose a bunch of well-paid software engineers burn out, so they quit to serve coffee in Seattle. This increase in labor supply will decrease the already low wages of existing Seattle baristas (say, by 5 percent), but liberals would balk at the notion that the state is even prima facie justified in criminalizing this career change.

\section{c. Social solidarity}

Some philosophers and economists worry that a big influx of immigrants could lessen the receiving country's social solidarity and social capital, a result that could be harmful for a variety of reasons (e.g., by lessening support for social safety nets and public goods). ${ }^{29}$

In reply, we return to an earlier point: cultural change can occur via internal factors such as speech just as it can occur via external factors such as immigration. Hundreds of religions and denominations enjoy nontrivial support in the United States. Surely we could boost social solidarity by pruning that number down a bit. We are not talking about imprisoning practitioners just creating restrictions that raise the costs of practicing the religions in question.

The same goes for political dissensus. As a thought experiment, suppose that there is a swell in the ranks of the "anarcho-primitivist" movement. This group, let us imagine, calls for the abolition of government, property and science. To restrict the growth of this movement, the United States government decides to constrain the rights of the anarcho-primitivists to carry out protest marches, to publish anarcho-primitivist literature and to produce anarchoprimitivist movies. Once again, it is far from clear that liberals would claim that the state is even prima facie justified in restricting anarcho-primitivists' freedom of speech, press and protest.

\section{Objections and Replies}

If the arguments in Sections 2 and 3 are correct, then defenders of immigration restrictions confront a tradeoff. They must choose between liberalism and immigration restrictions. If standard justifications for immigration restrictions succeed, then the same arguments can also justify infringements on core liberal freedoms. So, either immigration restrictions are justified or liberalism is, but not both. In this section, we will investigate whether defenders of immigration restrictions might evade this tradeoff by appealing to differences between the liberty to immigrate and other core liberal freedoms. We

${ }_{29}$ Macedo 2011. 
will argue that attempts to escape the tradeoff between liberalism and immigration restrictions fail.

\section{a. Asymmetry}

Here is a natural objection. Despite our argument in Section 1 that freedom of movement is a basic liberty partly in virtue of being a constituent of other basic liberties, you might think that an unlimited - or at least expansive freedom of movement is not a basic liberty alongside freedom of speech, print, religion, reproduction or occupational choice. So even if the reasons that allegedly weigh in favor of restricting liberty of movement also weigh in favor of restricting these other liberties, the protection of these other liberties carries extra weight. Consequently, the liberty-restricting reasons are weighty enough to outweigh our reasons to respect liberty of movement but not our reasons to respect liberty of speech, religion and so on. Call this the asymmetry objection.

The asymmetry objection can be fleshed out further with the help of David Miller's theory of basic human rights. Miller acknowledges that "freedom of movement qualifies as a basic human right" because it protects vital interests. ${ }^{30}$ However, only sufficient freedom of movement qualifies as a basic human right because a more extensive freedom is not needed to protect vital interests or meet basic human needs. People are only entitled, by right, to demand adequate options. ${ }^{31}$

The problem is that this reply overgeneralizes to any liberty that liberals think is basic. If people are entitled to only an adequate freedom of movement, are they also entitled to only an adequate freedom of speech, religion or occupational choice?32 Consider some earlier examples. If the state restricts couples to the production of two or three children, couples still have what could be regarded as "adequate" reproductive options. Being able to practice your religion for 40 hours a week (rather than, say, 24/7) is adequate. Being permitted to own 20 (rather than 30) books written in Esperanto is adequate. We only need some trimmed-down core of liberty of speech, religion and reproduction to protect our vital interests. Anything more is, in Miller's terms, bare freedom. Nevertheless, no state that we would consider liberal would impose these restrictions - at least not without extraordinary reasons.

Miller is aware of this line of objection. Here is his reply:

Allowing the state to judge which religions were to be permitted or which areas of the country people were to be allowed to travel to would also give it enormous

30 Miller (2005: 195).

31 Ibid.: 196.

32 A similar argument can be found in Oberman 2016 and Brezger and Cassee (forthcoming). 
power to oppress vulnerable groups. In order to fix the scope of particular human rights such as freedom of movement, we have to make judgments about the dangers that may follow from the misuse of state power. Permitting states to control the inward movement of people across their borders does not appear to present similar dangers, because the state's power to oppress outsiders is limited by the fact that these outsiders can choose which states they attempt to enter. ${ }^{33}$

In brief, Miller's response alleges that empowering the state to restrict freedom of immigration creates a lower risk of abuse than empowering it to restrict freedom of religion or internal movement.

We have two rebuttals. First, even if Miller is right that states are likely to misuse a power to restrict freedom of religion, this consideration does not fully explain the wrongness of empowering the state to restrict freedom of religion. To see why, just imagine a scenario in which the state will not misuse its powers (suppose we are living in a world where politicians are more West Wing than House of Cards). In this world, a law restricting the practice of Calvinism after 10 p.m. would still be unjustified - or at least, illiberal - even though there is no chance of this restriction spilling over to other cases.

Second, Miller says that "the state's power to oppress outsiders is limited by the fact that these outsiders can choose which states they attempt to enter." Miller is probably right that this consideration makes the restriction of movement within a state worse than the restriction of movement between states. But it does not explain why states are not justified in curtailing other freedoms within their borders. Here is a thought experiment. The U.S. and Canada share a completely open border. The U.S. passes a law restricting the practice of Calvinism after 10 p.m. That an American who opposes the law can set off for Canada fails to justify the law or render it consistent with liberalism.

\section{b. National partiality}

An objector might attempt to evade the tradeoff between immigration restrictions and liberalism by arguing that states have weaker moral duties to foreigners than they have to their own citizens. According to a common view, states have special obligations that require states to promote the interests of their own citizens. If states have special obligations to promote the interests of their own citizens, then it is plausible that states have weighty duties to respect the basic liberties of their citizens. These duties may explain why it is normally wrong for states to restrict citizens' freedoms. Yet states might only have weak duties to refrain from interfering with the freedoms of foreigners. As a result, it is relatively easy to justify limiting foreigners' freedom to immigrate, whereas it is difficult to justify restricting the liberties of

33 Miller (2013: 9). 
citizens. Let us call this the partiality objection. The partiality objection offers a way of evading the tradeoff between liberalism and immigration restrictions: in contrast to other restrictions on freedom, immigration restrictions are relatively unobjectionable because states only have weak moral reasons to avoid restricting the freedom of foreigners.

Yet the partiality objection is unsound. One problem with the partiality objection is that immigration restrictions in fact interfere with the freedoms of both foreigners and citizens. States that restrict immigration typically forbid citizens from helping transport migrants across borders, employing unauthorized migrants, sheltering them and facilitating the violation of immigration laws in other ways. More generally, immigration restrictions prevent citizens from associating with foreigners. The partiality objection says that states have stronger duties to refrain from interfering with citizens than they have to avoid interfering with foreigners. Even if we grant this claim, we should reject the conclusion that it is easy to justify immigration restrictions. If states have strong duties to respect the freedom of their own citizens, then these duties weigh against immigration restrictions, too.

A more fundamental problem with the partiality objection is that it is false that states' duties to respect the liberties of their own citizens are weightier than their duties to respect the liberties of foreigners. Perhaps states have stronger positive duties to provide resources or assistance to their citizens than they owe to foreigners. States may have a greater responsibility to provide their citizens with welfare benefits, health care or other entitlements. Yet it is implausible that states owe weightier negative duties to their own citizens than they owe to foreigners. That is, we should reject the view that states' duties to refrain from coercing or harming foreigners are weaker than their duties to avoid harming or coercing their own citizens when everything else is equal.

Here is an example to illustrate. Suppose that Sam is a citizen of the United States. Sam decides to assault and injure two innocent people, Bradley and Susan, who happen to be walking down the street where Sam lives. Let us stipulate that Sam's actions set back Bradley and Susan's interests to the same extent. But imagine that Bradley is a citizen of the United States and Susan is a Canadian tourist. It does not seem that Sam's attack on Susan is any less wrong than his attack on Bradley. Sam appears to have equally stringent negative duties to Susan and Bradley despite the fact that Susan is a foreigner. This judgment applies to state officials as well. Suppose that Sam is actually a police officer. So Sam is an agent of the state. Nonetheless, it is still just as wrong for Sam to assault Susan as it is for Sam to assault Bradley. ${ }^{34}$ These judgments seem relatively uncontroversial. Even authors who argue

34 For a similar argument, see Pogge (2006: 129-39). Our argument here also draws on Hidalgo (2014): 274-276. 
that we have special obligations to compatriots agree that negative duties to compatriots and foreigners have the same force. ${ }^{35}$

Immigration restrictions involve coercion. When states restrict immigration, they authorize state employees to use force or the threat of force to prevent foreigners from entering or residing in a state's territory. Immigration restrictions thus appear to violate negative duties. The partiality objection claims that states have weaker duties to refrain from interfering with the freedom of foreigners than the freedom of citizens. We can now see why this claim is incorrect. It is false that it is relatively easy to justify restricting the liberties of foreigners in virtue of the fact that states owe them weaker duties. This is false because negative duties to both citizens and foreigners are equally weighty and immigration restrictions violate negative duties. Consider another case: TSA agents at LaGuardia Airport should not forcibly restrict a Greek tourist's freedom of movement to stop her from buying the last Cinnabon or sitting at the last open seat in the airport chapel in order to secure those goods for a native New Yorker.

As noted, even if negative duties to citizens were weightier than negative duties to foreigners, this would still fail to justify immigration restrictions, as immigration restrictions coerce citizens as well. Consequently, we are unable to avoid the tradeoff between liberalism and immigration restrictions by appealing to the view that states owe stronger duties to their own citizens than they owe to foreigners.

But a related argument might ground an asymmetry between the claims of foreigners and those of citizens. This argument begins with the idea that states have stronger positive duties to their own citizens than they have to foreigners. On this view, states have weighty obligations to protect the interests of their citizens or assist them, while they have weaker positive duties to foreigners. As we discussed in Section 4, immigration can impose costs on citizens. Immigration may cause wage losses, unemployment, overconsumption of government services and so on. If immigration imposes large costs on a state's citizens, then this state's special obligation to protect the interests of citizens can override its negative duty to abstain from coercing potential immigrants. In other words, a state's weightier positive duty to its citizens can override the negative duties to respect the freedom of foreigners. Stephen Macedo develops a version of this argument. ${ }^{36} \mathrm{He}$ contends that compatriots have special obligations to one another. In particular, citizens have special duties to benefit disadvantaged citizens and immigration may impose significant costs on these citizens. According to Macedo, our special obligations to disadvantaged citizens sometimes override the moral reasons to permit immigration.

${ }^{35}$ See Miller (2008: 47-49).

36 Macedo 2007. 
The problem with this modified cost argument is that negative duties to foreigners normally defeat positive duties to compatriots. Imagine that a runaway trolley is about to hit one of your compatriots, but you can divert the trolley to a sidetrack where it will instead hit a foreigner. Even authors who believe that we have special obligations to compatriots agree that it is impermissible to divert the trolley in this case. ${ }^{37}$ The same is true in less extreme cases as well. Suppose that a rock is going to fall on one of your compatriots and break her arm, but you divert the rock so that it falls on a foreigner instead. Again, this seems wrong.

Finally, consider an analogy with special obligations to one's children. ${ }^{38}$ Suppose that your daughter is one of two finalists for a desirable job and both finalists are invited back for a job interview. Let us stipulate that your daughter is unemployed and would benefit a great deal from securing this position. Now, imagine that, on the day of the interview, you stop the other finalist in the street, physically restrain him and threaten him with harm if he resists you. As a result, the other finalist misses the interview and your daughter gets the job. Almost everyone would agree that your conduct is seriously wrong in this case.

Moreover, most people think that our special obligations to our compatriots are weaker and less demanding than our special obligations to our children. If negative duties to abstain from coercion outweigh special obligations to your child in cases such as this one, then we should expect that negative duties to refrain from coercing foreigners would typically outweigh positive duties to compatriots, at least when coercion would significantly set back the interests of foreigners. If negative duties normally defeat positive duties to compatriots when these duties come into conflict, then special obligations to compatriots are unable to explain why immigration restrictions are permissible. So this modified cost argument also fails to show that liberalism and immigration restrictions are consistent.

\section{Conclusion}

Suppose we are right that the standard arguments for immigration restrictions would also justify restrictions of core liberal freedoms. This conclusion poses a problem for advocates of the right to exclude. Most of the philosophical defenders of immigration restrictions are liberals. They accept that it is normally wrong for states to abridge core liberal freedoms, such as freedom of speech, occupational freedom and reproductive liberty. Thus, our

37 Miller considers this case and says: "I do not think it would be justifiable to switch the trolley from a track on which it was hurtling towards a compatriot on to a track on which it would hurtle towards a foreigner." But Miller also endorses partiality for compatriots. Miller (2008: 48-49).

38 We have adapted this case from Huemer (2010: 439). 
arguments threaten the coherence of their views. If we are right, then advocates of immigration restrictions must either achieve coherence by rejecting standard arguments for immigration restrictions or jettisoning liberalism.

We think that standard arguments for immigration restrictions should be rejected, although we lack the space to make a convincing argument here. Let us just note that dropping liberalism seems to pose a greater threat to the coherence of our views on justice than dropping substantive immigration restrictions. Of course, you might disagree. Even so, we think we have at least shown that the theoretical price of supporting immigration restrictions is steeper than it first appears. ${ }^{39}$

Christopher Freiman

Department of Philosophy

College of William \& Mary

cafreiman@wm.edu

Javier Hidalgo

Jepson School of Leadership Studies

University of Richmond

jhidalgo@richmond.edu

${ }^{39}$ For helpful feedback on earlier drafts, thanks are due to Sahar Akhtar and the Normative Theory of Immigration Working Group. 


\section{References}

Benn, S. (1988) A Theory of Freedom, Cambridge: Cambridge University Press.

Blake, M. (2003) "Immigration," in R. G. Frey and C. H. Wellman, eds., A Companion to Applied Ethics, Malden, MA: Blackwell, pp. 224-37.

Brezger, J. and Cassee, A. (forthcoming) "Debate: Immigrants and Newcomers by Birth Do Statist Arguments Imply a Right to Exclude Both?” Journal of Political Philosophy.

Carens, J. (2013) The Ethics of Immigration, New York: Oxford University Press.

Cole, P. and Wellman, C. H. (2011) Debating the Ethics of Immigration: Is There a Right to Exclude? New York: Oxford University Press.

Dustmann, C., Frattini, T. and Preston, I. (2013) "The Effect of Immigration Along the Distribution of Wages," Review of Economic Studies 80: 145-73.

Feinberg, J. (1987) Harm to Others, Oxford: Oxford University Press.

Gaus, G. (2005) "The Place of Autonomy Within Liberalism," in J. Christman and J. Anderson, eds., Autonomy and the Challenges to Liberalism, Cambridge: Cambridge University Press, pp. 272-306.

Heath, J. (1997) "Immigration, Multiculturalism, and the Social Contract," Canadian Journal of Law and Jurisprudence 10: 343-61.

Hidalgo, J. (2014) "Self-Determination, Immigration Restrictions, and the Problem of Compatriot Deportation," Journal of International Political Theory 10: 261-82.

Huemer, M. (2013) The Problem of Political Authority, New York: Palgrave Macmillan. (2010) "Is There a Right to Immigrate?" Social Theory and Practice 36: 429-61.

Isbister, J. (2000) "A Liberal Argument for Border Controls: Reply to Carens," International Migration Review 34: 629-35.

Kukathas, C. (2005) "The Case for Open Immigration," in A. Cohen and C. H. Wellman, eds., Contemporary Debates in Applied Ethics, Malden, MA: Blackwell, pp. 207-20.

Locke, J. (1960/1689) "The Second Treatise of Government," in P. Laslett, ed., Two Treatises of Government, Cambridge: Cambridge University Press, pp. 283-446.

Macedo, S. (2011) "When and Why Should Liberal Democracies Restrict Immigration?" in R. Smith, ed., Citizenship, Borders, and Human Needs, Philadelphia: University of Pennsylvania Press, pp. 301-23.

(2007) "The Moral Dilemma of U.S. Immigration Policy: Open Borders versus Social Justice?" in C. Swain, ed., Debating Immigration, New York: Cambridge University Press, pp. 63-81.

Mill, John Stuart (1963) Collected Works of John Stuart Mill, Volume 21. J. M. Robson, ed., Toronto: University of Toronto Press.

Miller, D. (2016) "Is There a Human Right to Immigrate?” in S. Fine and L. Ypi, eds., Migration in Political Theory: The Ethics of Movement and Membership, Oxford: Oxford University Press, pp. 11-31.

(2013) "Border Regimes and Human Rights," Law and Ethics of Human Rights 7: 1-23. (2008) National Responsibility and Global Justice, New York: Oxford University Press. (2005) "Immigration: The Case for Limits," in A. Cohen and C. Wellman, eds., Contemporary Debates in Applied Ethics, Malden, MA: Blackwell, pp. 193-206.

Moore, M. (2015) A Political Theory of Territory, Oxford: Oxford University Press.

National Research Council (1997) The New Americans: Economic, Demographic, and Fiscal Effects of Immigration, J. Smith and B. Edmonston, eds., Washington, D.C.: National Academies Press.

Oberman, K. (2016) "Immigration as a Human Right," in S. Fine and L. Ypi, eds., Migration in Political Theory: The Ethics of Movement and Membership, Oxford: Oxford University Press, pp. 32-56.

Ottaviano, G. and Peri, G. (2012) "Rethinking the Effect of Immigration on Wages," Journal 
of the European Economic Association 10: 152-97.

Peri, G. (2012) "The Effect of Immigration on Productivity: Evidence from U.S. States," Review of Economics and Statistics 94: 348-58.

and Sparber, C. (2009) "Task Specialization, Immigration, and Wage," American Economic Journal: Applied Economics 1: 135-69.

Pevnick, R. (2014) Immigration and the Constraints of Justice, New York: Cambridge University Press.

Pogge, T. (2006) World Poverty and Human Rights, Cambridge: Polity Press.

Rawls, J. (1999) A Theory of Justice, Cambridge, MA: Harvard University Press.

Scheffler, S. (2010) Equality and Tradition, Oxford: Oxford University Press.

Sparrow, R. (forthcoming) "If People Were Movies? Free Speech and Free Association," Journal of Political Philosophy.

Walzer, M. (1983) Spheres of Justice: A Defense of Pluralism and Equality, New York: Basic Books.

Wellman, C. H. (2008) "Immigration and Freedom of Association," Ethics 119: 109-41.

Woodward, J. (1992) "Commentary: Liberalism and Migration," in B. Barry and R. E. Goodin, eds., Free Movement: Ethical Issues in the Transnational Migration of People and of Money, University Park, PA: Pennsylvania State University Press, pp. 59-84. 